\title{
EL PAPEL DEL SANTUARIO DE DELFOS DURANTE LA GUERRA DEL PELOPONESO
}

\author{
The Role of the Sanctuary of Delphi during Peloponnesian War
}

\author{
Javier Jara Herrero \\ javijara@usal.es \\ Universidad de Salamanca
}

Fecha de recepción: 02/03/2020

Fecha de aceptación: 16/03/2020

Resumen: Las relaciones entre la polis de Esparta y el santuario de Delfos eran más que fluidas ya antes de comenzar la guerra del Peloponeso, el conflicto panhelénico que concluyó con la asunción del control político y militar de Grecia por parte de los lacedemonios y del cual el oráculo délfico no se mantuvo al margen. Pero ¿hasta qué punto Apolo se posicionó del lado espartano? ¿Resultaron sus intervenciones cruciales para la victoria final de la liga del Peloponeso? Este artículo indaga en las maniobras diplomáticas délficas ejecutadas durante el transcurso de la contienda para tratar de conocer el peso que las actividades oraculares ejercieron en ambos bandos, apoyándose a tal efecto en los relatos proporcionados por diversos autores antiguos (siendo Tucídides, en tanto que relator y participante de la guerra, la fuente principal) y en los numerosos estudios de la historiografía moderna al respecto.

Palabras clave: Civilización griega; Mitología; Edad antigua; Religión antigua; Militarismo.

Abstract: The relationship between Sparta and the sanctuary of Delphi was more than fluid before the Peloponnesian War, the panhellenic conflict that ended with the assumption of political and military control of Greece by the Lacedemons and from which the Delphic Oracle was not kept out. But to what extent did Apollo position himself on the Spartan side? Did his interventions prove decisive to the final victory of the Peloponnesian League? This paper investigates the Delphic diplomatic maneuvers carried out during the course of the conflict to try to know the weight that the oracular activities exerted on both sides, relying, for this purpose, on the stories provided by various ancient authors (being Thucydides, as a repporteur and participant in the war, the main source) and in the numerous studies of modern scholarship in this regard.

Keywords: Greek Civilization; Mythology; Antiquity; Ancient Religions; Militarism. 
SUMARIO: 1. Introducción. 2. El compromiso délfico con la legitimidad de la "causa» espartana. 3. La presión de Delfos hacia la "paz de Nicias». 4. El oráculo en la fase final de la guerra. 5. A modo de conclusión. 6. Fuentes. 7. Referencias bibliográficas.

\section{INTRODUCCIÓN}

En el año 431 a. C. comenzó el gran conflicto que traería la implantación de la hegemonía militar espartana por todo el territorio griego. La "guerra del Peloponeso», como la historiografía posterior ha denominado esta conflagración, supuso la culminación de una escalada de tensiones entre las dos alianzas preponderantes del espacio político helénico: la liga del Peloponeso, una symmachia formada por las principales ciudades de la península homónima y encabezada por Esparta, se enfrentó a la liga de Delos, una suerte de imperio talasocrático liderado por Atenas e integrado por buena parte de los estados del Egeo y de la costa minorasiática que surgió en el 477 a. C. como respuesta a los reveses sufridos por sus miembros durante las recién finalizadas guerras médicas. Una de las características de los procesos bélicos radica en que las pertinentes maniobras militares no constituyen los únicos factores suficientes para asegurar el triunfo de los contendientes. El apoyo de las diversas instituciones, castrenses o no, puede resultar determinante en el resultado de las operaciones. Esta es la razón por la cual el objetivo de esta investigación, lejos de centrarse en las tácticas adoptadas por uno u otro bando o bien en enfrentamientos puntuales, se centrará en la actividad desempeñada por la institución religiosa griega más importante en el siglo $V$ a. C., el oráculo de Delfos, que, como veremos, contribuyó significativamente mediante sus profecías y respaldos al desarrollo del acontecimiento militar que inspiró la gran obra del historiador Tucídides. El ateniense es, precisamente, la principal fuente histórica tomada en consideración para la elaboración de este artículo. No obstante, también encontramos en Jenofonte, Plutarco o Pausanias magníficos testimonios para la comprensión del papel desempeñado por el santuario délfico durante las tres décadas que se demoró el conflicto. A los manuscritos legados por los autores de la Antigüedad se unen los estudios realizados por la historiografía moderna, de entre los que destacan los desempeñados por Michael Scott (uno de los máximos exponentes en lo que a la investigación sobre el santuario se refiere), el estadounidense Donald Kagan y, dentro del mundo hispanohablante, César Fornis. Todo ello servirá para analizar la influencia ejercida por el lugar sagrado sobre los agentes bélicos y demostrar que las supuestas decisiones tomadas por Apolo Piteo al respecto de la guerra cobraron una considerable trascendencia en la evolución de la misma. 


\section{EL COMPROMISO DÉLFICO CON LA LEGITIMIDAD DE LA "CAUSA" ESPARTANA}

El proceso por el que se desencadenó la guerra del Peloponeso puede resultar complejo y, en cierta medida, confuso. La formación de la liga de Delos tras las guerras médicas y la incapacidad de Esparta de frenar su expansión crearon, durante el periodo que separa ambas guerras, conocido como «Pentecontecia», un mundo griego altamente polarizado entre una y otra facción (Fliess, 1966). Aunque fueron múltiples los acontecimientos que condujeron a la apertura de las hostilidades, Kagan (1969) señala dos factores sin los cuales la guerra podría no haberse materializado: el choque de intereses atenienses y corintios en los conflictos de Corcira y Potidea y el «Decreto de Mégara», una resolución de la ekklesia que castigaba la defección megarense con duras medidas económicas que obligaron a este estado a pedir la intervención espartana en el Ática. La asamblea de la liga del Peloponeso se reunió para deliberar al respecto y comprobar la soberbia de los heraldos atenienses destacados en Esparta (Th., I, 74-76), tras lo cual la mayoría de los integrantes de la alianza consideró «que los atenienses ya eran culpables y que había que declararles la guerra inmediatamente» (Th., I, 79).

Para entonces, Esparta mantenía unas excelentes relaciones con el santuario délfico (Defradas, 1954), fruto de la vinculación de la propia historia de la polis con la institución religiosa a través de los siglos. La tradición espartana había enlazado hábilmente su sistema sociopolítico, recibido de la mano del mítico Licurgo, con el oráculo, de manera que los pilares del edificio institucional lacedemonio (la diarquía, la gerousia o consejo de ancianos y la apella o asamblea ciudadana) quedaron indisolublemente ligados a los preceptos de Apolo (véase Scott, 2015; Nafissi, 2018; Nafissi, 2019). Tal era la sintonía entre ambas entidades que Esparta es el único estado de la antigua Grecia en el que se documenta la existencia de unos personajes responsables de enviar las pertinentes embajadas al lugar: recibían el nombre de pythioi o "pitios» y, según Heródoto (VI, 57.2-4), eran «los encargados de ir a consultar a Delfos» ${ }^{1}$. Los diarcas espartanos, por su parte, supieron explotar convenientemente el recurso a la religión para legitimar sus acciones geopolíticas en el marco de la expansión territorial y posterior asunción de la hegemonía de la península del Peloponeso acaecidas en la etapa final del Arcaísmo (Domínguez Monedero, 2010; Fornis y Domínguez Monedero, 2014). Podría decirse, pues, que las autoridades espartanas procuraron asociar los destinos de su patria con los del propio santuario, en la medida en que pudiera beneficiar a los lacedemonios.

Esta armonía existente entre Esparta y el santuario podría explicar, probablemente, la posición de la sacerdotisa en los momentos inmediatamente anteriores al

1 Sobre los pitios, su sistema de elección y sus atribuciones, véase Fontenrose (1978), Malkin (1999) y Lévy (2003). 
estallido del conflicto. Poco antes de celebrar la asamblea de la liga del Peloponeso que concluyó con el quorum favorable a la declaración de guerra, los espartanos habrían enviado a sus embajadores a buscar el apoyo del santuario (Fornis, 2016). La respuesta de la pitia, recogida por Tucídides (I, 118.3), resulta sorprendentemente clara para una institución cuyas profecías destacaban por su ambigüedad y la dificultad de su interpretación, toda vez que "contestó, según se dice, que si combatían con todas sus fuerzas la victoria sería suya, y les declaró que él mismo les apoyaría, tanto si era invocado como sin serlo». Aun con el respaldo apolíneo, Esparta envió heraldos a Atenas con el fin de exigir que los atenienses «dejaran libres a los griegos». Ante la negativa de Pericles, los lacedemonios se convirtieron en adalides de una guerra de liberación y consiguieron ganarse las simpatías de buena parte del mundo griego del momento (Murcia Ortuño, 2017)2. Pese a que algunos de los aliados peloponesios comenzaron abiertamente las hostilidades antes de las maniobras espartanas (Fornis 2016), el conflicto comenzaría oficialmente con la invasión lacedemonia del Ática liderada por el diarca Arquidamo II en mayo del año 431 a. C., dando paso a su primera fase, la conocida como «guerra arquidámica».

Así pues, el santuario de Delfos se mantuvo del lado de la liga del Peloponeso al comienzo de la guerra. Las fuentes indican, incluso, el patrocinio económico del colegio sacerdotal délfico a los esfuerzos bélicos espartanos, lo que se desprende del discurso corintio ante la asamblea peloponesia que Tucídides recogió en su obra. En este fragmento se deja entrever la posibilidad de que Delfos subvencionase parte del conflicto contra Atenas:

[...] Por muchas razones es natural que venzamos, en primer lugar, porque les aventajamos en número y en experiencia bélica; en segundo lugar, porque todos sin distinción acudimos prestos a ejecutar lo ordenado. Y respecto a la marina, que es donde reside su poder, nos equiparemos una escuadra con los recursos que cada cual tiene y con el dinero de Delfos y Olimpia. En efecto, si hacemos que se nos conceda un préstamo seremos capaces con un sueldo mayor de usurparles los remeros extranjeros [...] (Th., I, 121).

Del extracto tucidídeo se destila que el apoyo económico brindado por el santuario de Delfos pudo ser determinante para los planes espartanos de terminar con el conflicto de la manera más rápida posible. Una victoria naval para los peloponesios habría significado la destrucción de la marina ateniense, donde descansaba el poderío militar de la liga de Delos. Además, una Esparta suficientemente acaudalada habría podido provocar la defección de los remeros atenienses, en su

${ }^{2}$ Esparta supo granjearse una fama de enemiga de las tiranías que, en el siglo $V$ a. C., había arraigado en la Hélade y que fue recogida por varios autores de la Antigüedad: Hdt. (V, 92); Arist. (Pol. 1310b-1311b); Aesch. (II, 77); Plb. (IV, 81.13); Plu. (Mor. 859C-D). Estudios que cuestionan esta política lacedemonia son los de Paradiso (1995), Thommen (2017) e Iriarte (2019). 
mayoría mercenarios extranjeros (Kagan, 1974). Sin embargo, ni Esparta ni su alianza contaban con un tesoro capaz de financiar tales planes, lo que hizo necesaria la interpelación al oráculo délfico. No está claro hasta qué punto se materializaron los préstamos de dinero procedente de Delfos y Olimpia (Parke y Wormell, 1956) ${ }^{3}$, pero la mera mención por parte de Tucídides muestra que las arcas de los miembros de la liga del Peloponeso, incluso combinadas, se mostraban insuficientes para sufragar una flota que hiciera frente a la ático-délica (cfr. Kallet-Marx, 1993). El hecho de que la guerra continuara durante esta primera fase sin un claro bando vencedor aumenta la probabilidad de que tales empréstitos se llevaran a cabo.

El apoyo délfico a la "causa» espartana, con todo, no radicó únicamente en proporcionar un hipotético soporte económico a la liga del Peloponeso. Tucídides informa de que el oráculo sancionó la fundación de una nueva colonia por parte espartana, situada en una zona de vital importancia estratégica:

Por esta época, los lacedemonios fundaron su colonia de Heraclea, en Traquinia [en la zona sur de Tesalia]. [...] Al mismo tiempo les parecía muy oportuno el establecimiento de la ciudad con vistas a su guerra con Atenas. [...] En resumen, estaban interesadísimos en colonizar esta zona. En primer lugar, pues, consultaron al dios de Delfos, y una vez obtenida su aprobación, despacharon los colonos (espartanos y periecos) invitando a que marcharan con ellos a cuantos griegos quisieran, excepción hecha de los jonios, aqueos y algunos otros pueblos (Th., III, 92).

El santuario de Delfos, en tanto que actor fundamental en lo que a las empresas colonizadoras griegas se refiere (Delcourt, 1955; Scott, 2015), puso de manifiesto su adhesión a la alianza peloponesia con la exclusión de la etnia jonia a la que, tradicionalmente, se adscriben a los áticos. Por lo tanto, no es de extrañar que la desilusión hacia el oráculo creciera de forma exponencial dentro de la sociedad ateniense. Así lo revelan las resentidas representaciones que los principales autores trágicos de la Atenas del momento plasman en sus respectivas obras sobre Delfos: Eurípides dibuja el santuario como un lugar dirigido por un colegio sacerdotal corrompido por "el hijo de Agamenón " ${ }^{4}$, en referencia a Esparta (E., Andr. 1085-1100) o como un juez imparcial (E., Andr. 1160-1165), mientras que Aristófanes recurre al sarcasmo para describir a un oráculo que deja de lado a la polis con la que, poco tiempo atrás, mantuvo fuertes vínculos (Ar., Eq. 999-1011). Sófocles, por su parte,

${ }^{3}$ Acerca de las relaciones entre Esparta y el santuario de Olimpia, véase Thommen (2013).

${ }^{4}$ Los lacedemonios habían construido una tradición que les convertía en depositarios de la herencia aquea de Agamenón: así Boedeker (1998); Salapata (2011); Fragkaki (2016).

${ }^{5}$ El cómico se refiere a la reconstrucción del santuario de Apolo por parte de la aristocrática familia ateniense de los Alcmeónidas tras el incendio que devastó Delfos a mediados del siglo vi. Cfr. Zahrnt (1989); Scott (2015). 
atribuye al propio Apolo Pítico un carácter rencoroso y para nada misericordioso (S., OT. 720-725).

Convendría, llegados a este punto, reflexionar acerca de las causas por las que el santuario délfico mostró tan inquebrantable fidelidad a la liga del Peloponeso en estos primeros años de la guerra. En este sentido, debemos retrotraernos hasta la segunda guerra sagrada, uno de los hitos que demuestran que el lapso entre la expulsión de Jerjes y el conflicto tratado en este artículo no fueron en absoluto pacíficos. Tras la victoria de la coalición panhelénica en su pugna contra el imperio persa en el 479 a. C., las poleis más poderosas de la Hélade se disputaron el apoyo del santuario de Delfos mediante la construcción de fastuosas edificaciones y complejos escultóricos que advirtiesen a sus visitantes del respaldo del oráculo a su particular facción. Los atenienses fueron los primeros en materializar este hábito (Zahrnt, 1989). Mientras en los primeros años de la Pentecontecia Esparta siguió consultando a la pitia délfica sin destacarse en sus obsequios al santuario, Atenas consumó una monopolización del espacio sagrado, al tiempo que modelaba la liga ático-délica. De este modo, entre el 480 y el 460 a. C., los atenienses colmaron Delfos de tesoros, estoas, estatuas y monumentos conmemorativos, de manera que el lugar quedó inconfundiblemente controlado por el estado democrático (véase Amandry, 1984; Hansen, 1989; Jacquemin, 1999 y Scott, 2010). Atenas también influyó militarmente en el santuario, pues la asistencia de sus hoplitas fue determinante para mantener Delfos y su entorno religioso dentro del espacio político de Fócide, estado que se había hecho con el control de la región de Dóride, en la que se encontraba el templo apolíneo ${ }^{6}$.

Aproximadamente a mediados del siglo $\mathrm{V}$ a. C., ante la amenaza de que Atenas mermara significativamente su influencia en el santuario, Esparta reaccionó para restablecer el equilibrio de poder en Delfos. Hasta esa fecha las ofrendas y obsequios espartanos se habían caracterizado por su sencillez, como correspondía a una ciudad-estado con un carácter como el laconio, capaz de enjuiciar a aquellos espartiatas que se atribuyesen la autoría de ofrendas distinguidas, tal y como ocurrió con Pausanias el Regente (Fornis, 2015). Ahora bien, habida cuenta las intenciones atenienses y la pérdida de autonomía del santuario, Esparta decidió emprender una ambiciosa campaña de recuperación de la hegemonía política sobre el recinto. A la llegada de varias ofrendas monumentales procedentes del estado peloponesio (Scott, 2015) se unió un inesperado movimiento: el envío de hoplitas lacedemonios al templo de Apolo para restituir la histórica independencia violada por Atenas y, de paso, asegurarse la lealtad de su colegio sacerdotal (Cartledge, 1979 y Low, 2006). Tucídides ya se hizo eco del acontecimiento en su obra:

${ }^{6}$ A este respecto, es interesante el apunte de Scott (2015), quien recuerda que Delfos habría permanecido independiente de cualquier entidad política hasta ese momento. 
[...] Después de esto, los lacedemonios emprendieron la llamada Guerra Sagrada, se adueñaron del templo de Delfos y se lo restituyeron a los delfios. A su vez, algo más tarde, los atenienses, cuando aquéllos se retiraron, hicieron otra expedición, se apoderaron de él y se lo devolvieron a los focidios (Th., I, 112.5).

Durante estos años, que Scott (2015) acota entre el 449 y el 445 a. C., se repitieron las expediciones espartanas y atenienses a Delfos, con el objetivo de controlar su santuario para garantizar su independencia o someter el lugar a Fócide, respectivamente. El enfrentamiento se saldó, como cuenta Tucídides en el extracto traído a colación, con la reintegración del lugar sagrado en la órbita focidia (véase también Plu., Per. 21.2; D.S. XI, 81-82), pero, mediante las suntuosas ofrendas citadas, Esparta consiguió desbancar a su polis adversaria en lo que al control sobre el oráculo se refiere. En agradecimiento por la defensa del lugar, los espartiatas fueron recompensados con la promanteía, el derecho a consultar el oráculo por delante de otros visitantes del santuario (Scott, 2015), al tiempo que una de las ofrendas otorgadas al santuario por el rey Creso de Lidia fue convenientemente modificada en su inscripción para que pareciera que la habían ofrecido los propios espartanos (Hdt., I, 51-53). Los mismos habitantes de Delfos donaron una estatua de un lobo de bronce, en honor a la historia de un lobo que ayudó a defender el templo (Prontera, 1981; Scott, 2015). La segunda guerra sagrada puso de manifiesto que, en los años anteriores a la guerra del Peloponeso, el dominio de Delfos se hizo fundamental para asegurar la preponderancia política sobre Grecia. El papel desempeñado por el oráculo en la política helénica había alcanzado tal importancia que, en este periodo caracterizado por el recrudecimiento de las relaciones entre Esparta y Atenas, ambas poleis se procuraron la incorporación del santuario en sus correspondientes esferas de influencia, mediante la fuerza si era necesario.

En esta primera fase de la guerra, la sintonía entre el santuario délfico y el estado lacedemonio fue completa. Delfos no sólo se encontraba en el territorio controlado por la liga del Peloponeso, sino que había restringido el acceso al templo de Apolo a los peregrinos procedentes de los estados integrantes de la liga de Delos (Kagan, 1974). No obstante, el apoyo del oráculo a los intereses espartanos no fue suficiente para lograr una rápida victoria. Habida cuenta de la hegemonía marítima de los atenienses y sus aliados y de la superioridad de los hoplitas espartiatas que asolaban el Ática, la guerra parecía encontrarse en un punto muerto una década después de su inicio.

\section{LA PRESIÓN DE DELFOS HACIA LA «PAZ DE NICIAS"}

En el año 421 a. C. se firmó una tratado anhelado por ambos contendientes. Atenas se encontraba económicamente exhausta a raíz de las continuas invasiones 
del Ática llevadas a cabo por las fuerzas peloponesias y Esparta, por su parte, deseaba devolver a sus hogares a los casi trescientos hoplitas capturados por los atenienses tras la batalla de Esfacteria, ciento veinte de los cuales pertenecían a familias conspicuas (Murcia Ortuño, 2017), que Atenas, en primer término, se negaba a repatriar sin que los peloponesios restituyeran ciertas ciudades de la península Calcídica (Plu., Nic. 10.8-9). A esta razón, Esparta debió sumar el fin del «tratado de los Treinta Años», mediante la que se paralizaba su conflicto con Argos, sempiterna némesis espartana desde el siglo VI a. C. (cfr. Fornis y Domínguez Monedero, 2014) que, con el devenir de los acontecimientos, terminó engrosando la alianza encabezada por Atenas (Fornis, 1993). La paz se levantó sobre el principio jurídico del uti possidetis, suponiendo una vuelta a la situación anterior a la guerra en lo que a las posesiones territoriales se refiere (Kagan, 1974; Fornis, 2016).

La conocida como "paz de Nicias» se materializó merced a dos figuras fundamentales: el propio Nicias, político y general ateniense que dio nombre al tratado, $y$, por parte espartana, el diarca Plistoánax, hijo de Pausanias el Regente, reinstaurado en el trono en el año 426 a. C. El Agíada se mostró, durante toda su vida política, favorable a la paz y a la amistad con Atenas y a limitar la actividad espartana a lo concerniente al Peloponeso. Fue precisamente su hipotético acercamiento a los intereses atenienses lo que le valió el exilio en el 445 tras una infructuosa invasión del solar ático y la posterior acusación de un soborno que habría redundado en su deposición (Kagan, 2009). Plistoánax residió entonces en la misma Atenas, donde mantuvo su posición tendente al fin de las hostilidades entre la liga del Peloponeso y su homóloga délica. Pese al destierro impuesto por la sociedad espartiata, este personaje no permaneció políticamente inactivo. Consciente de la devoción mostrada por el pueblo de Esparta a los designios del oráculo de Delfos, el que fuera diarca elaboró una estrategia dirigida a la recuperación del poder: junto a su hermano Aristocles, consiguió sobornar a la pitia para que emitiera serias amenazas a todo espartano que acudiera a pedir consejo al santuario, tal como nos transmite Tucídides:

Lo acusaban, en efecto, de haber persuadido, en unión de su hermano Aristocles, a la sacerdotisa de Delfos para que en repetidas ocasiones respondiera a los teoros ${ }^{7}$ lacedemonios que allí llegaran el siguiente oráculo: "Haced regresar desde tierra extranjera a su patria la simiente del semidiós hijo de Zeus; pues, en caso contrario, araréis con reja de plata» (Th., V, 16.2).

7 Atendiendo a Dillon (1997), los teoros eran los magistrados que, en calidad de mensajeros sagrados, eran enviados por una ciudad a un oráculo. Debemos suponer, por lo tanto, que los teoros espartanos eran los pitios. 
El mensaje que el historiador ateniense atribuye a la sacerdotisa apolínea debió de calar en la sociedad espartana, dado que Plistoánax regresó a su polis, diecinueve años después de decretarse su exilio, "con los mismos coros e idénticos sacrificios con los que, antiguamente, cuando la fundación de Lacedemonia, entronizaron a sus reyes» (Th., V, 16.3), ritos que hacen pensar en una maniobra propagandística, lanzada desde el círculo agíada, que equiparaba la vuelta del diarca con el mítico retorno de los Heraclidas (Lupi, 2014). Inmediatamente comenzaron las conversaciones de paz con Nicias, que cristalizarían cinco años después en un armisticio concertado por cincuenta años (Th., V, 18.3). Plistoánax también tenía motivaciones personales para buscar la paz con la symmachia ateniense: el mismo Tucídides $(V, 16.1)$ revela que, tras volver a Esparta, el diarca era acusado por sus adversarios políticos "cada vez que la ciudad sufría algún revés» y que «enojado, pues, por estas calumnias, pensaba que no se produciría ninguna desgracia mientras hubiera paz» (Th., V, 17.1; véase Kagan, 1981).

En el momento de la rúbrica del tratado, el santuario de Delfos se encontraba en el centro de atención de las partes implicadas en la guerra. Siguiendo, una vez más, el relato tucidídeo, durante las conversaciones anteriores al documento final, en el 423, ya existía un borrador en el que se encontraba una cláusula relativa a las posibilidades de cualquier griego de acudir a consultar a la pitia:

En lo que respecta al santuario y al oráculo de Apolo Pitio, acordamos que pueda consultarlo todo el que quiera, sin engaño y libremente, según las normas tradicionales. Éste es el parecer de los lacedemonios y de sus aliados presentes. Y enviarán además heraldos a los beocios y a los focenses para intentar, en la medida de lo posible, convencerlos (Th., IV, 118.1).

En este extracto se pone de manifiesto que, al sentimiento de frustración hacia el oráculo existente en la sociedad ateniense, habría que sumar la dificultad que entrañaba el acceso de los suplicantes de Atenas al santuario. En efecto, y pese a los intentos por la paz, las relaciones entre atenienses y beocios continuaban siendo más que tensas $y$, dado que Beocia se encontraba en el camino sagrado que unía Atenas y Delfos, era necesario el permiso de los primeros para practicar los ritos oraculares pertinentes (Dougherty, 1996). Esta problemática, de la que ya se lamentaban algunos de los autores contemporáneos (Ar., Au. 189194; E., Ion 370-375, 439-444), tuvo como resultado un considerable descenso de las embajadas atenienses enviadas a Delfos durante este periodo, en comparación con las llevadas a cabo durante las guerras médicas sesenta años atrás (Scott, 2015). La cuestión délfica vertebró, finalmente, parte de los términos del armisticio ulterior: 
En relación con los santuarios comunes, que quien lo desee pueda ofrecer sacrificios, acudir, consultar los oráculos y enviar teoros según los usos tradicionales, libremente, tanto por tierra como por mar. El santuario y el templo de Apolo en Delfos, y los propios delfios, gozarán de autonomía tanto tributaria como judicial, tanto en lo referente a sus personas como a sus tierras, en conformidad con los usos tradicionales (Th., V, 18.2).

Repentinamente, el santuario de Delfos asumió una actitud de estricta neutralidad que le aseguró el reconocimiento de ambos contendientes de la guerra y, dicho sea de paso, de sus opulentas ofrendas. Es probable que su colegio sacerdotal comenzara a dudar de las posibilidades reales de Esparta de ganar la guerra, máxime tras la derrota del ejército peloponesio en Esfacteria; o que se produjeran sobornos dedicados a provocar la defección délfica de la «causa» espartana. No obstante, el cambio de parecer de Delfos puede obedecer más a razones de índole económica. La reducción de ingresos procedentes de las ofrendas atenienses o de sus aliados no habrían pasado inadvertidas para las autoridades délficas, que habrían puesto en funcionamiento su poderosa maquinaria diplomática para asegurarse un abundante flujo de capital ${ }^{8}$. Tal práctica no constituiría una novedad en la historia política del santuario, salpicada de anécdotas en las que sus administradores consintieron corruptelas e intrigas, promovidas a diversos títulos privados, que se tradujeron en pingües beneficios financieros para el lugar sagrado. Convendría, al hilo, recordar la defensa de los Alcmeónidas atenienses sostenida por la pitia tras la construcción de un nuevo y suntuoso templo de Apolo sufragado por esta aristocrática familia a finales del siglo vı a. C. (Parke y Wormell, 1956); o la protección póstuma del honor de Pausanias el Regente, quien intentó ganarse la simpatía oracular tras el secuestro de la ofrenda que los griegos, en conjunto, dedicaron al dios pítico tras la expulsión de los invasores persas en el 479 a. C. (Fornis, 2015).

La presión ejercida por el santuario en aras de la restauración en el trono espartano de Plistoánax podría, por lo tanto, entenderse en el marco de las ambiciones délficas por aumentar su patrimonio. Su clase sacerdotal no vaciló en dejar de lado la política de "agradecimiento» a Esparta por la defensa prestada antes del estallido de la guerra para pasar a convertirse en un actor principal en la consecución de una paz claramente ventajosa para las arcas de Delfos. La actitud de la pitia y su respaldo, soborno mediante o no, a los intereses de Plistoánax supusieron un desafortunado punto de inflexión para los propósitos espartanos: el aura de «liberadores de los griegos» atribuido a los lacedemonios se desvaneció con rapidez cuando se dio prioridad a la recuperación de los prisioneros de Esfacteria sobre las exigencias de

8 No debemos juzgar con los criterios del presente la práctica de los líderes religiosos délficos consistente en procurarse el mayor número de ofrendas posible. Según la tradición épica griega recogida en h.Hom., h.Ap. 527-542, el mismo Apolo, al ser preguntado por los sacerdotes de su nuevo santuario acerca de su supervivencia, les ordenó sobrevivir merced a la generosidad de aquellos que fueran a consultar el oráculo. 
los aliados de la liga del Peloponeso, furibundos ante la idea de un tratado que les negaba significativas ventajas territoriales y que les llevó a plantearse seriamente la continuidad en la symmachía liderada por Esparta (Fornis, 2016).

Mientras tanto, en Atenas, el joven orador Alcibíades comenzaba a aumentar su notoriedad política. Este miembro de la familia Alcmeónida era un ferviente defensor de agresividad de la política exterior ateniense, aun a costa de la paz que, de hecho, fue firmada por políticos que no escucharon sus opiniones por su corta edad (Sealey, 1976). Una vez nombrado estratego de las fuerzas terrestres atenienses, Alcibíades supo aprovechar la debilidad atravesada por Esparta para formar la llamada «cuádruple alianza» junto a Argos, Mantinea y Elis (Plu., Alc. 15.1), estados que compartían su rencor hacia el estado lacedemonio y su aperturismo hacia las reformas democráticas (cfr. Fornis, 1993). Ambas facciones terminaron enfrentándose en la batalla hoplítica de Mantinea en el año 418 a. C., resultando triunfantes las armas espartanas que, sin embargo, no quisieron continuar el conflicto, temerosas de un una Atenas capaz de disputar a Esparta la hegemonía militar terrestre (Powell, 2018).

La devoción a los dioses no parecía ser el punto fuerte del controvertido Alcibíades. El fracaso del ejército aliado en Mantinea motivó los preparativos para la célebre expedición ateniense a Sicilia del 415 a. C., en cuya víspera tuvo lugar el escándalo religioso conocido como "Hermocópidas»: poco antes de la partida de una gran flota hacia Italia, se descubrió que todos los hermai (representaciones del dios Hermes adornadas con un falo que se usaban como mojones o pilares en los

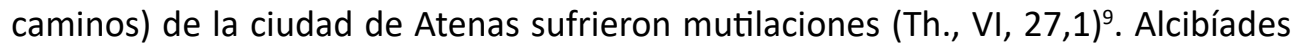
fue acusado del sacrilegio y, además, de profanar los misterios de Eleusis (Plu., Alc. 19), constituyendo este hecho un mal presagio para el destino de la armada. La aventura ateniense a Sicilia se saldó con un estrepitoso desastre para Alcibíades al perder la nada desdeñable cantidad de cincuenta mil hombres y más de doscientos navíos (Fornis, 2016), un resultado que algunos autores quieren relacionar (obviamente, desde un punto de vista poético) con la decisión del estratego de lanzar su empresa de ultramar sin consultar anteriormente con el oráculo de Delfos (Scott, $2015)^{10}$. El general fue llamado a juicio, pero, antes de su celebración, huyó a Esparta, de donde también tuvo que desertar tras los rumores escarceos amorosos con la esposa del rey espartiata Agis II (cfr. Plu., Lys. 22). Cuando dejó Esparta, regresó a Atenas como strategos autokrator, esto es, general plenipotenciario. Tras la derrota de Notio, se retiró a sus posesiones en Tracia y luego pasó a Frigia, donde murió.

${ }^{9}$ Si bien Tucídides deja claro que las mutilaciones de los hermai se realizaron en sus rostros, algunos investigadores como Romilly (1997) estiman que el sacrilegio se realizó mediante la amputación de los falos de estos pilares, apoyándose en el relato de Aristófanes (Lys. 1093-1095) y en el hecho de que su forma resultaría más susceptible de sufrir el vandalismo.

10 Sin embargo, Plutarco (Mor. 403B) informa de una consulta a la pitia sobre el estado de la flota cuando esta se encontraba ya en alta mar. La evasiva de la sacerdotisa no fue del agrado de los atenienses. 


\section{EL ORÁCULO EN LA FASE FINAL DE LA GUERRA}

El cese de las actividades bélicas alcanzado en el 421 a. C. con la «paz de $\mathrm{Ni}$ cias» demostró ser, en palabras del propio Tucídides (V, 26.2), hypoulos eirene, es decir, una paz ficticia: «un periodo en el que los dos bandos no se restituyeron ni recuperaron lo que habían comprometido. Y aún más, ambas partes cometieron nuevas violaciones del tratado». Mientras Esparta recuperaba el entusiasmo tras la victoria en Mantinea (lo que, a su vez, solucionó las sospechas de cobardía que recayeron sobre sus hoplitas tras la debacle de Esfacteria), la moral de la sociedad ateniense quedó seriamente quebrada tras la fallida expedición de Alcibíades a Sicilia y las consiguientes amenazas de defección por parte de algunos integrantes de la liga ático-délica (Kagan, 1981; Murcia Ortuño, 2017). La guerra se reanudó oficialmente en el 413 a. C., subyaciendo como casus belli la invasión de suelo laconio llevada a cabo por Atenas, que otorgó a los lacedemonios «un motivo más que justificado para defenderse contra los atenienses» (Th., VI, 105.2; véase también Powell, 1980). El suceso dio comienzo al periodo del conflicto conocido como «guerra decélica», a tenor del establecimiento de la base de operaciones espartana en el fuerte de Decelia, cerca de la misma Atenas; o "guerra jónica», toda vez que la costa oeste de la península de Anatolia se convirtió en un significativo escenario de operaciones bélicas (Kagan, 1987).

Si bien parte de la historiografía moderna parece aceptar que el santuario délfico volvió a posicionarse del lado de la liga del Peloponeso en este último estadio (Parke y Wormell, 1956), lo cierto es que las fuentes antiguas apenas ofrecen documentación de actividades políticas de la entidad religiosa. Sí sabemos que la symmachia ateniense continuó con su decepción hacia Apolo (apenas envió heraldos al oráculo durante estos diez años) y que, en contrapartida, la alianza peloponesia se esforzó por erigir ofrendas monumentales (Scott, 2015). La sintonía de la alianza espartana con Delfos contrastaba, además, con el deterioro que comenzaban a sufrir los complejos escultóricos atenienses ofrecidos décadas atrás. El biógrafo Plutarco deja entrever que los monumentos del santuario comenzaron a representar, en esta época, no solo las victorias de aquellas poleis oferentes, sino también su suerte:

En Delfos había una estatua de oro de Palas que se sostenía sobre una palmera de bronce, ofrenda de la ciudad [Atenas] por las victorias de las guerras médicas. Durante muchos días unos cuervos se acercaron volando hasta ella y la picotearon; arrancaron el fruto de la palmera, que era de oro, y lo arrojaron al suelo. [...] Cuando un oráculo ordenó a los atenienses traer de Clazómenas a la sacerdotisa de Atenea, ellos hicieron venir a esa mujer. Se llamaba Hesiquia (Paz). Y eso era, según parece, lo que la divinidad aconsejaba a la ciudad en aquel momento: conservar la paz (Plu., Nic. 13.5-6). 
El oráculo, cuya veracidad es aceptada (Parke y Wormell, 1956), es uno de los pocos testimonios antiguos que respaldan el apoyo del colegio sacerdotal délfico a los intereses espartanos. En el devoto mundo griego, donde el destino del santuario panhelénico por antonomasia estaba indisolublemente unido al de los estados con los que se relacionaba, nadie parecía dudar, en la última década del siglo $\mathrm{V}$ a. C., que la victoria en el conflicto que agitó la Hélade se encontraba de forma cada vez más clara en manos espartanas.

Con todo, Esparta necesitaba algo más que su superioridad terrestre para doblegar al enemigo ático-délico. Los lacedemonios comprendieron que, para obtener la victoria, era imperativo dotarse de una flota que hiciera frente a la potente marina ateniense $y$, a fin de procurársela, consiguieron la financiación del imperio persa, enemistado con Atenas desde décadas atrás. Este hecho marca una destacable diferencia con el primer periodo de la guerra en lo referente a las relaciones espartanodélficas: si, al inicio de la guerra, el santuario de Delfos podría haber sufragado los costes de una armada peloponesia (vid. supra), en esta última fase el apoyo de su colegio sacerdotal, de existir, parece materializarse únicamente en sus profecías. Delfos, por tanto, habría retirado su soporte económico a la liga del Peloponeso, si bien mantuvo una política favorable a este bando.

El liderazgo de la nueva escuadra espartana recayó en el espartiata Lisandro, artífice de la victoria final peloponesia (cfr. Bommelaer, 1981; Due, 1987). El inicio del fin de la guerra del Peloponeso llegó en el año 405 a. C., en la batalla naval de Egospótamos, en la que Lisandro sorprendió a la fuerza naval ateniense varada en tierra. Atenas no pudo reponerse del varapalo y comenzó las negociaciones de paz al año siguiente. Esparta y sus aliados decidieron preguntar, una vez más, a la sacerdotisa de Apolo acerca del proceder adecuado ante los vencidos. Buena parte de los vencedores, de entre los que destacaban por su clamor corintios y tebanos, reivindicaron la destrucción hasta los cimientos de Atenas y la reducción de su población a la más humillante esclavitud, más por miedo al hegemónico estado lacedemonio que surgía de esta conflagración que del odio que podrían profesar a su enemigo derrotado (Fornis, 2016). La pitia, no obstante, respondió que los vencedores tenían que respetar el hogar común de Grecia (Parker, 2000). Finalmente, Lisandro decidió «no esclavizar a una ciudad griega que había hecho grandes y bellas cosas» (X., HG. 2.2.20), en clara referencia al servicio prestado por Atenas a principios de ese mismo siglo en la guerra que enfrentó a helénicos y persas. Pese a la actitud mostrada por el exitoso navarco de Egospótamos, las condiciones impuestas por la liga del Peloponeso a Atenas fueron considerablemente duras: la reducción de su escuadra a doce trirremes, la demolición de los «Muros Largos» y la obligación de seguir a los espartanos a la guerra si se diera el caso son algunas de las cláusulas que la Boule ateniense hubo de aceptar en el año 404 a. C. (Fornis, 2016). Las intenciones espartanas, al coartar la autonomía de la polis democrática sin llegar a arrasarla, pasaba por poner coto al progresivo fortalecimiento de Tebas en la zona 
central de Grecia $^{11}$, algo inadmisible para las autoridades lacedemonias (véase Ste. Croix, 1972).

El santuario de Delfos fue el escenario escogido por Lisandro para conmemorar la trascendental victoria sobre Atenas. De acuerdo con el relato que, al respecto, nos proporciona Plutarco (Lys. 18.1), «con el botín Lisandro erigió en Delfos una estatua suya en bronce y otras de cada uno de los navarcos, además de las estrellas de los Dioscuros en oro». El geógrafo Pausanias describió el complejo escultórico con una mayor precisión, nombrando en su obra los personajes retratados, que ascendían a treinta y ocho (Paus., 10.9.9). Con esta construcción se ponía en evidencia que Delfos era el lugar donde se plasmaban los vaivenes de la historia griega. Los monumentos levantados por las autoridades espartanas superaban en lujo y en tamaño a los construidos por sus otrora enemigos en otros momentos anteriores: el grupo escultórico de Egospótamos triplicaba el tamaño de la ofrenda otorgada por Atenas tras la batalla de Maratón del 490 a. C., mientras que la donación llevada a cabo por el rey espartano Agis utilizando el dinero del botín capturado durante sus campañas fue colocado sobre una inmensa columna para asegurar su visibilidad (Scott, 2015).

Parece claro que el oráculo no había practicado una postura de neutralidad en los últimos años de la guerra del Peloponeso, razón que podría haber motivado tales muestras de reconocimiento hacia el santuario por parte de las autoridades espartanas. Obviando el más que plausible apoyo de Apolo Pitio al bando peloponesio, Esparta tenía motivos para sentirse en deuda, si tomamos como cierta la hipótesis que nos presenta a Delfos como entidad subsidiaria de la armada de la liga del Peloponeso en la primera fase del conflicto. Asimismo, el santuario habría cosechado un mayor beneficio económico manteniendo (o recuperando) la alianza tácita con Esparta con la que había comenzado el enfrentamiento. Las profecías délficas en aras de la "paz de Nicias», en tanto que maniobra política que redundara en una vuelta de Atenas y de sus ofrendas al ya abarrotado lugar sagrado, no consiguieron su objetivo. Probablemente, para no perder también los ingresos derivados de los obsequios procedentes del Peloponeso, el colegio sacerdotal considerara necesario mantener unas estrechas relaciones con los estados integrantes de la alianza espartana.

El final de la guerra del Peloponeso, en el año 404 a. C., marca el comienzo de la hegemonía espartana en la Hélade, en lo que la mayoría de la doctrina coincide en llamar «segundo imperio espartano» (Forrest, 1968; Fornis, 2008). El mundo griego tardó poco tiempo en darse cuenta de que la victoria de Esparta, lejos de significar una «liberación» del yugo ateniense, solo representó un cambio de autoridad en la mayoría de las poleis, pues Lisandro, el navarco vencedor de la marina ateniense en Egospótamos, estableció progresivamente regímenes de talante oligárquico, las

${ }^{11}$ Sobre Tebas y la confederación beocia: Pascual González (1995). 
denominadas «decarquías» (véase Cavaignac, 1924; Bommelaer, 1981) en las ciudades que tomó. La implantación de estos sistemas políticos a lo largo y lo ancho de Grecia fue acompañada, por lo general, de un gran flujo de riquezas y de oro hacia Esparta y hacia el propio Lisandro, que permitieron a este último alzar su lujoso monumento en el santuario de Delfos para inmortalizar su paso por la historia helénica. De esta manera, Esparta, cuyas leyes prohibían taxativamente la acumulación de fortuna (X., Lac. 7.2-5), experimentó un imparable enriquecimiento a raíz de su férreo imperialismo en los años posteriores al conflicto. Los orgullosos lacedemonios parecieron olvidar, curiosamente, el legendario oráculo délfico que advertía de que «la codicia, y ninguna otra cosa, será la ruina de Esparta» (D.S., VII, 12.5).

\section{A MODO DE CONCLUSIÓN}

Con el paso de los siglos, el santuario de Apolo en Delfos se convirtió en uno de los centros místicos más importantes de la Hélade, a lo que contribuyeron diversos factores, de entre los que destaca su vertebración del proceso colonial griego, especialmente durante el Arcaísmo. Esta transformación fue acompañada de una paulatina corrupción del colegio sacerdotal délfico, como muestran los episodios relacionados con la familia Alcmeónida de Atenas y con el regente espartano Pausanias. Para mediados del siglo v a. C., el lugar se había convertido en el núcleo religioso del mundo griego. No obstante, Delfos no era ya una mera institución dedicada a la administración de los ritos religiosos relacionados con Apolo pítico, sino que representaba un organismo político más preocupado de su porvenir económico: el oráculo de este dios ofrecía sus vaticinios al mejor postor o al organismo que beneficiara en mayor medida sus inquietudes. Así podemos entender el respaldo que la pitia ofreció a los intereses espartanos, en tanto que garantía de la independencia délfica frente a las ambiciones focidias que se materializaron en la segunda guerra sagrada y que amenazaban con mermar significativamente la opulencia de la clase administradora délfica. Por ello, la profecía que aseguraba la ayuda apolínea para Esparta en los momentos inmediatamente anteriores a la guerra y el posterior patrocinio de la armada peloponesia formaban no tanto una asistencia desinteresada como una medida de defensa ante los peligros que podría entrañar la actividad política de Atenas, vinculada a las aspiraciones focidias.

La desilusión ateniense hacia el oráculo, como se ha señalado, repercutió negativamente en la afluencia de visitantes áticos al santuario y, por consiguiente, de sus ofrendas. El santuario necesitó un ardid diplomático que se tradujera en una normalización de las relaciones délficas con el resto del mundo griego. A este respecto, la adhesión a las reclamaciones de Plistoánax sirvió para establecer un armisticio que, en primer término, restablecería las embajadas a Delfos de los estados enemigos de Esparta. No era suficiente con conseguir la paz: el santuario se aseguró 
de capitalizar parte de las cláusulas de la "paz de Nicias», de acuerdo con el relato de Tucídides, garantizando la libertad de consulta de todo griego. De esta manera, mientras las hostilidades continuaban en este periodo de paz armada, el lugar podría presentar una imagen de neutralidad. Aun así, parece que Atenas no recuperó el entusiasmo por ofrendar a Apolo, quizá debido a la ausencia de éxitos militares que plasmar en el recinto sagrado. Temiendo perder también el fomento de una polis tan devota como Esparta, a Delfos no le quedó más remedio que volver a apostar por situarse del lado de la liga del Peloponeso en la última fase de la guerra. Ahora bien, el colegio sacerdotal no permitiría un gasto como el que habría supuesto el patrocinio de la armada espartana en la década anterior. Las profecías oraculares, de ser cierto el testimonio de Plutarco, estarían encaminadas a recomendar a los atenienses la capitulación, honrosa o no.

La jugada diplomática surtió el efecto deseado. Esparta se convirtió en indiscutible hegemon de Grecia y eligió el santuario délfico para conmemorar tanto la victoria sobre Atenas como la asunción de esta nueva posición de preponderancia con la erección del colosal complejo escultórico que homenajeaba el triunfo de Lisandro en Egospótamos, un monumento que, sin duda, no habría pasado desapercibido para los visitantes al templo y cuya finalidad era, precisamente, advertir de la superioridad de las armas espartanas. El éxito de Delfos no fue solo económico, también político: el santuario se consolidó como la institución religiosa panhelénica más importante de la Antigüedad, un lugar en el que los hitos históricos quedaban grabados en piedra y bronce. No es fruto del azar, a la luz de esta realidad, que fuera a finales del siglo $V$ a. $C$. cuando se inscribieron las célebres máximas que coronaban el templo de Apolo y que aconsejaban a los viajeros: "conócete a ti mismo», «nada en exceso» y «un juramento conduce a la perdición» (PI., Chrm. 164E), tres principios atribuidos, según la tradición antigua, a los Siete Sabios de Grecia. La guerra del Peloponeso, pues, convirtió a Delfos en el verdadero ombligo del mundo antiguo.

\section{FUENTES}

Aristófanes. Comedias I. Los acarnienses, Los caballeros. Madrid: Editorial Gredos. 1995. [Edición de Luis Gil Fernández].

Aristófanes. Comedias II. Las nubes, Las avispas, La paz, Los pájaros. Madrid: Editorial Gredos. 2007. [Edición de Luis M. Macía Aparicio].

Aristófanes. Comedias III. Lisístrata, Tesmoforiantes, Ranas, Asambleístas, Pluto. Madrid: Editorial Gredos. 2007. [Edición de Luis M. Macía Aparicio]. 
Aristóteles. Política. Madrid: Editorial Gredos. 1988. [Edición de Manuela García Valdés].

Diodoro de Sicilia. Biblioteca Histórica. Libros IV-VIII. Madrid: Editorial Gredos. 2004. [Edición de Juan José Torres Esbarranch].

Diodoro de Sicilia. Biblioteca Histórica. Libros IX-XII. Madrid: Editorial Gredos. 2006. [Edición de Juan José Torres Esbarranch].

Eurípides. Tragedias I. El cíclope, Alcestis, Medea, Los Heraclidas, Hipólito, Andrómaca, Hécuba. Madrid: Editorial Gredos. 1991. [Edición de Juan Antonio López Férez].

Eurípides. Tragedias II. Suplicantes, Heracles, Ion, Las troyanas, Electra, Ifigenia entre los tauros. Madrid: Editorial Gredos. 1985. [Edición de José Luis Calvo Martínez].

Esquines. Discursos. Testimonios y cartas. Madrid: Editorial Gredos. 2002. [Edición de José María Lucas de Dios].

Heródoto. Historias. Madrid: Cátedra. 2016. [Edición de Manuel Balasch].

Homero. Himnos homéricos. La «batracomiomaquia». Madrid: Editorial Gredos. 1978. [Edición de Alberto Bernabé Pajares].

Jenofonte. Constituciones políticas griegas. Constitución de Esparta. Madrid: Alianza Editorial. [Edición de Antonio Guzmán Guerra].

Jenofonte. Helénicas. Madrid: Editorial Gredos. 1994. [Edición de Orlando Guntiñas Tuñón].

Pausanias. Descripción de Grecia. Libros VII-X. Madrid: Editorial Gredos. 2008. [Edición de María Cruz Herrero Ingelmo].

Platón. Diálogos I. Apología, Critón, Eutifrón, Ion, Lisis, Cármides, Hipias menor, Hipias mayor, Laques, Protágoras. Madrid: Editorial Gredos. 1985. [Edición de J. Calongue Ruiz, E. Lledó Íñigo y C. García Gual].

Plutarco. Obras morales y de costumbres (Moralia) VI. Madrid: Editorial Gredos. 1995. [Edición de Francisca Pordomingo Pardo y José Antonio Fernández Delgado]. 
Plutarco. Obras morales y de costumbres. (Moralia) IX. Madrid: Editorial Gredos. 2002. [Edición de Vicente Ramón Palerm y Jorge Bergua Cavero].

Plutarco. Vidas paralelas. I. Lisandro-Sila, Cimón-Lúculo, Nicias-Craso. Madrid: Editorial Gredos. 2007. [Edición de Jorge Cano Cuenca, David Hernández de la Fuente y Amanda Ledesma].

Plutarco. Vidas paralelas. II. Solón-Publícola, Temístocles-Camilo, Pericles-Fabio Máximo. Madrid: Editorial Gredos. 2008. [Edición de Aurelio Pérez Jiménez].

Plutarco. Vidas paralelas. III. Coriolano-Alcibíades, Paulo Emilio-Timoleón, PelópidasMarcelo. Madrid: Editorial Gredos. 2006. [Edición de Aurelio Pérez Jiménez y Paloma Ortiz].

Polibio. Historias. Libros I-IV. Madrid: Editorial Gredos. 1981. [Edición de Alberto Díaz Tejera y Manuel Balasch Recort].

Sófocles. Tragedias. Madrid: Editorial Gredos. 1981. [Edición de Assela Alamillo].

Tucídides. Historia de la Guerra del Peloponeso. Madrid: Alianza Editorial. 2014 [Edición de Antonio Guzmán Guerra].

\section{REFERENCIAS BIBLIOGRÁFICAS}

Amandry, P. (1984). Notes de topographie et d'architecture delphiques. Bulletin de Correspondance Hellenique, 108(8), pp. 295-315. https://doi.org/10.3406/ bch.1984.1852.

Boedeker, D. (1998). Hero Cult and Politics: The bones of Orestes. En C. Dougherty y L. Kurke (eds.), Cultural Poetics in Archaic Greece: Cult, performance, politics (pp. 167-170). Cambridge: Cambridge University Press.

Bommelaer, J.-F. (1981). Lysandre de Sparte. Histoire et traditions. Bibliothèque des Écoles Françaises d'Athènes et de Rome, 240, París-Atenas.

Cartledge, P. (1979). Sparta and Lakonia: A Regional History. 1300 to 362 BC. Londres: Routledge. https://doi.org/10.4324/9780203472231.

Cavaignac, E. (1924). Les dékarchies de Lysandre. Revue des Études Historiques, 90, pp. 285-316. 
Defradas, J. (1954). Les thèmes de la propagande delphique. París: Les belles lettres.

Delcourt, M. (1955). L'oracle de Delphes. París: Payot.

Dillon, M. (1997). Pilgrims and Pilgrimage in Ancient Greece. Londres: Routledge.

Domínguez Monedero, A. (2010). Destrucción de la naturaleza y castigo divino: Cleómenes de Esparta y el bosque sagrado de Argos. En S. Montero y M. C. Cardete (eds.), Naturaleza y religión en el mundo clásico. Usos y abusos del medio natural (pp. 125-142). Madrid: Sígnifer Libros.

Dougherty, C. (1996). Democratic Contradictions and the Synoptic Illusion of Euripides' Ion. En J. Ober y C. W. Hendrick (eds.), Demokratia: A Conversation on Democracies, Ancient and Modern (pp. 249-270). Princeton: Princeton University Press.

Due, B. (1987). Lysander in Xenophon's Hellenica. Classica \& Mediaevalia, 38, pp. 53-62.

Fliess, P. J. (1966). Thucydides and the Politics of Bipolarity. Louisiana State Univ. Press.

Fontenrose, J. (1978). The Delphic Oracle. Its Responses and Operations with a Catalogue of Responses. Los Angeles: University of California Press. https://doi. org/10.1525/9780520331310.

Fornis, C. (1993). Esparta y la cuádruple alianza. 420-418 a. C. Memorias de Historia Antigua, 13-14, pp. 77-104.

Fornis, C. (2008). Grecia exhausta. Ensayo sobre la guerra de Corinto. Hypomnemata 175, Göttingen: Vandenhoeck \& Ruprecht.

Fornis, C. (2015). Pausanias el Regente y la stásis en la clase dirigente espartiata tras las guerras médicas. Polis. Revista de ideas y formas políticas de la Antigüedad Clásica, 27, pp. 27-38.

Fornis, C. (2016). Esparta. La historia, el cosmos y la leyenda de los antiguos espartanos. Sevilla: Universidad de Sevilla. 
Fornis, C. y Domínguez Monedero, A. (2014). El conflicto entre Argos y Esparta por la Tireátide y el culto a Apolo Piteo. Gerión, 32, pp. 79-103. https://doi. org/10.5209/rev_GERI.2014.v32.46666.

Forrest, W. G. (1967). A History of Sparta. London: Bristol Classical Press.

Fragkaki, M. (2016). The "Repatriation" of Orestes and Theseus. Antesteria, 5, pp. 285-302.

Hansen, E. (1989). Epigraphica bellica on the dedication of the Athenian portico at Delphi. Classica \& Medievalia, 40, pp. 133-134.

Iriarte, U. (2019). Las advertencias de Quilón y Solón sobre la tiranía de Pisístrato. Panta Rei. Revista Digital de Ciencia y Didáctica de la Historia, pp. 113-128. https://doi.org/10.6018/pantarei/2019/6.

Jacquemin, A. (1999). Offrandes monumentales à Delphes. París: École Française d'Athènes.

Kagan, D. (1969). The Outbreak of the Peloponnesian War. Londres: Cornell University Press.

Kagan, D. (1974). The Archidamian War. Londres: Cornell University Press.

Kagan, D. (1981). The Peace of Nicias and the Sicilian Expedition. Londres: Cornell University Press.

Kagan, D. (1987). The Fall of the Athenian Empire. Londres: Cornell University Press.

Kagan, D. (2009). La guerra del Peloponeso. Barcelona: Editora y Distribuidora Hispano Americana.

Kallet-Marx, L. (1993). Money, Expense and Naval Power in Thucydides' History 1-5.24. Los Ángeles: University of California Press.

Lévy, E. (2003). Sparte: histoire politique et sociale jusqu'à la conquête romaine. París: Points.

Low, P. A. (2006). Conmemorating the Spartan war dead. En A. Powell y S. Hodkinson (eds.), Sparta and War (pp. 85-109). Swansea: The Classical Press of Wales. https://doi.org/10.2307/j.ctvvnb23.6. 
Lupi, M. (2014). Il ritorno del re. Una nota sulla seconda ascesa al trono di Pleistoanatte (Thuc. 5, 16). Quaderni Urbinati di Cultura Classica, 108, pp. 125130.

Malkin, I. (1999). Delphoi and the founding of social order in archaic Greece. Métis. Anthropologie des mondes grecs anciens, 4(1), pp. 129-153. https://doi. org/10.3406/metis.1989.933.

Murcia Ortuño, J. (2017). Esparta. Madrid: Alianza Editorial.

Nafissi, M. (2018). Lykourgos the Spartan "Lawgiver": Ancient Beliefs and Modern Scholarship. En A. Powell (coord.), A Companion to Sparta (pp. 93-123). Hoboken: Blackwell. https://doi.org/10.1002/9781119072379.ch4.

Nafissi, M. (2019). Esparta. En C. Fornis (coord.), Mito y arqueología en el nacimiento de ciudades legendarias de la Antigüedad (pp. 25-57). Sevilla: Editorial Universidad de Sevilla.

Paradiso, A. (1995). Tempo della tradizione, tempo dello storcio: Thuc. I. 18 e la storia arcaica spartana. Storia della storiografia, 28, pp. 35-45.

Parke, H. W. y Wormell, D. E. W. (1956). The Delphic Oracle. Volume I: The History. Oxford: Blackwell.

Parker, R. (2000). Greek States and Greek Oracles. En R. Buxton (ed.), Oxford Readings in Greek Religion (pp. 76-108). Oxford: Oxford University Press.

Pascual González, J. (1995). Tebas y la confederación beocia en el periodo de la guerra de Corinto (395-386 a. C.). (Tesis inédita de doctorado). Universidad Autónoma de Madrid, Madrid.

Powell, A. (1980). Athens' Difficulty Sparta's Opportunity: Causation and the Peloponnesian War. L'antiquité classique, 49, pp. 96-114. https://doi. org/10.3406/antiq.1980.1966.

Powell, A. (2018). Sparta's Foreign - and Internal - History, 478-403. En A. Powell (coord.), A Companion to Sparta (pp. 291-319). Hoboken: Blackwell. https:// doi.org/10.1002/9781119072379.ch11.

Prontera, F. (1981). Gli Alcmeonidi a Delfi: Un ipotesi su Erodoto I, 51, 3-4. Revue Archéologique, Nouvelle Série, 2, pp. 253-258. 
Romilly, Jacqueline de (1997). Alcibiade ou les dangers de l'ambition. París: Editions de Fallois.

Salapata, G. (2011). The Heroic Cult of Agamemnon. Electra, 1, pp. 39-60.

Scott, M. (2010). Delphi and Olympia: The Spatial Politics of Panhellenism in the Archaic and Classical Periods. Cambridge: Cambridge University Press.

Scott, M. (2015). Delfos. Historia del centro del mundo antiguo. Barcelona: Ariel.

Sealey, R. (1976). A History of the Greek City States, 700-338 B. C. Berkeley: University of California Press. https://doi.org/10.1525/9780520342750.

Ste. Croix, G. E. M de (1972). The Origins of the Peloponnesian War. Londres: Bristol Classical Press.

Thommen, L. (2013). Spartas Verhältnis zu Elis und Olympia. En N. Birgalias, K. Buraselis, P. Cartledge, A. Gartziou-Tatti y M. Dimopoulou (eds.), War-Peace and Panhellenic Games. In Memory of Pierre Carlier (pp. 329-344). Atenas: Kardamitsa Publishing.

Thommen, L. (2017). Sparta. Verfassungs- und Sozialgeschichte einer griechischen Polis. Stuttgart: Metzler. https://doi.org/10.1007/978-3-476-04331-3.

Zahrnt, M. (1989). Delphi, Sparta und die Rückführung der Alkmeoniden. Zeitschrift für Papyrologie und Epigraphik, 76, pp. 297-307. 